NBER WORKING PAPER SERIES

\title{
PUBLIC RADIO IN THE UNITED STATES: \\ DOES IT CORRECT MARKET FAILURE \\ OR CANNIBALIZE COMMERCIAL \\ STATIONS?
}

\author{
Steven T. Berry \\ Joel Waldfogel
}

Working Paper 6057

\section{NATIONAL BUREAU OF ECONOMIC RESEARCH 1050 Massachusetts Avenue \\ Cambridge, MA 02138 \\ June 1997}

We thank Shelly Cagner of Arbitron, James Duncan of Duncan's American Radio, Craig Oliver of the Radio Research Consortium, and Young Lee and Janice Jones of the Corporation for Public Broadcasting for help getting the data. Seminar participants at Georgetown, UCLA, Wharton, Yale, and the Harvard/MIT public economics workshop provided useful comments. We alone are responsible for the views, as well as any errors, in the paper. This paper is part of NBER's research programs in Industrial Organization, Law and Economics, and Public Economics. Any opinions expressed are those of the authors and not those of the National Bureau of Economic Research.

(C) 1997 by Steven T. Berry and Joel Waldfogel. All rights reserved. Short sections of text, not to exceed two paragraphs, may be quoted without explicit permission provided that full credit, including $\mathbb{C}$ notice, is given to the source. 
Public Radio in the United States: Does it Correct

Market Failure or Cannibalize Commercial Stations?

Steven T. Berry and Joel Waldfogel

NBER Working Paper No. 6057

June 1997

JEL Nos. H41, L33, L82

Industrial Organization, Law and Economics, and Public Economics

\begin{abstract}
Radio signals are pure public goods whose total value to society is the sum of their value to advertisers and listeners. Because broadcasters can capture only part of the value of their product as revenue, there is the potential for a classic problem of underprovision. Small markets have much less commercial program variety than larger markets, suggesting a possible underprovision problem. Public funding of radio broadcasting targets programming in three formats - news, classical music, and jazz - with at least some commercial competition. Whether public support corrects a market failure depends on whether the market would have provided similar services in the absence of public broadcasting. To examine this we ask whether public and commercial classical stations compete for listening share and revenue. We then directly examine whether public stations crowd out commercial stations. We find evidence consistent with the view that public broadcasting crowds out commercial programming in large markets, particularly in classical music and to a lesser extent in jazz. Although the majority of government subsidies to radio broadcasting are allocated to stations without commercial competition in their format (thereby possibly correcting inefficient market underprovision), roughly a quarter of subsidies support direct competition with existing commercial stations.
\end{abstract}

Steven T. Berry

Department of Economics

Yale University

37 Hillhouse Avenue

New Haven, CT 06520

and NBER

steveb@econ.yale.edu
Joel Waldfogel

Department of Economics

Yale University

37 Hillhouse Avenue

New Haven, CT 06520

and NBER

wald@econ.yale.edu 


\section{Introduction}

Radio signals are pure public goods whose total value to society is the sum of their value to advertisers and listeners. While programming with total value in excess of its costs should be provided, the market provides only programming that attracts enough listeners so that advertising revenue covers costs. ${ }^{1}$ Because broadcasters can capture only part of the value of their product, there is the potential for a classic problem of underprovision. Some programming with total value in excess of its cost will not be provided. At the same time, because of free entry there is a possibility of excess entry of stations into popular formats. ${ }^{2}$ Because there is no reason to expect the market to provide the right amount of radio broadcasting, it is interesting to examine the determinants of broadcast provision that does occur.

This study examines market and government provision of radio broadcasting in the U.S. The first goal of this study is to identify possible areas of underprovision by the market. Although commercial firms provide most types of programming in most markets, the market provides a much greater variety of programming in larger markets. This suggests that any problem of inefficient underprovision - failure to provide programming with total value in excess of its costs occurs in small markets. For example, while the market provides classical music programming in most of the 25 largest U.S. markets, commercial stations provide classical music in only 9 of the remaining markets among the 165 examined in this study. A similar pattern holds for jazz as well as programming targeted at black and Hispanic audiences.

The U.S. is one of the few nations relying almost exclusively on the market for provision of radio broadcasting. ${ }^{3}$ Most European countries fund broadcasting with radio or combined radio/television receiver license fees. While commercial broadcasting in the U.S. generated $\$ 8.9$

${ }^{1}$ See Samuelson (1954) for a discussion of correct public goods allocation. See also Bradford and Hildebrandt (1977) for a discussion of valuing public goods based on demand for their complements.

2 If a type of programming attracts enough listeners in a market to generate advertising revenue sufficient to finance multiple stations, the market will provide multiple stations even if they offer identical programming. Berry and Waldfogel (1996) examines the problem of excess entry into commercial radio broadcasting and is a companion to the present study.

${ }^{3}$ See Head (1985) for a discussion of broadcast finance around the world. 
billion in revenue in 1993 (see Duncan, 1994), total government support for radio in 1993 totaled only $\$ 160$ million. ${ }^{4}$ While small overall, government support for radio is targeted at nonprofit ("public") radio stations offering a small number of programming formats: news, classical music, and jazz. Commercial firms are also active in the provision on each of these types of programming. Whether public support alleviates possible underprovision problems depends on whether the market would have provided the services offered by public broadcasters in their absence. At the same time, whether public and commercial programming can displace one another - and whether commercial service can adequately replace public programming - depends on whether the two forms actually offer similar programming. We have no direct evidence on this. However, we can study the substitutability of public and commercial programming indirectly. Do public and commercial classical stations compete for listening share and revenue? Do public stations crowd-out commercial stations? ${ }^{5}$ If public and commercial stations within a format draw each other's listeners and revenue, we can infer that their programming is somewhat substitutable. In this study we present new data, and our approach is to describe the data and document basic relationships. We defer to subsequent work attempts to derive functional forms for estimation from underlying models of utility. ${ }^{6}$

We present evidence consistent with the hypothesis that public and commercial broadcasting offer substitute programming in jazz and, especially, classical music. We find explicit evidence of a crowding out relationship between commercial programming in jazz and especially classical music. We find no evidence that public and commercial news programming are substitutable. Given our estimated relationships, we estimate the extent of commercial provision of classical and jazz programming that would occur in the absence of public programming. We also examine the distribution of government support across markets and

\footnotetext{
${ }^{4}$ Stations supported by the Corporation for Public Broadcasting (CPB) receive a total of $\$ 160$ million in combined federal, state, and local government support.

${ }^{5}$ This study is related to other studies asking whether government crowds out private activity, such as Cutler and Gruber (1996).

${ }^{6}$ See Berry and Waldfogel (1996) for such a study of commercial radio broadcasting.
} 
broadcast programming formats, asking whether public support appears to be targeted to offset underprovision by the market. Does government support foster programming in markets that would otherwise be unserved by such programming? Or does government support for public broadcasting serve mainly to cannibalize service that the market would otherwise provide?

Our study proceeds as follows. First we place the question in context in section 2 with a brief discussion of market and optimal provision of broadcasting services. We then turn to positive description of the provision of radio broadcasting. Section 3 describes the data employed in the study. Section 4 documents how commercial and public provision of broadcasting services vary with market size. Some formats are rarely provided by the market in small cities, suggesting a possible underprovision problem that government intervention might correct. Section 4 also documents that listening increases with available product variety, indicating that the extent of available programming variety matters to people and, by extension, that the absence of programming variety has negative consequences. In section 5 we examine whether public and commercial programming appear to be substitutes. Based on the estimated relationship between public and commercial stations, we simulate the commercial response to the hypothetical absence of public classical and jazz broadcasting. Section 6 discusses the pattern of government support for public broadcasting, by size of market and whether it receives commercial service. We conclude with a discussion of next steps for the research.

Public funding of radio broadcasting has recently come under fire in the U.S. On December 6, 1994 Speaker of the U.S. House of Representatives Newt Gingrich remarked that, "One of the things we're going to do this year, I hope, is to zero out the Corporation for Public Broadcasting, which has been eating taxpayers' money" (DeWitt, 1994). While it is impossible to quantify the dollar benefits of public broadcasting without information on the benefit of programming to listeners, our analysis can shed light on the effect of public funding on commercial provision. In particular, we can determine whether suitable substitutes for public programming would be supplied by the market in the absence of public broadcasting. For 
example, can we identify circumstances in which publicly supported programming displaces commercial activity? In that case the public support might have been better placed elsewhere.

\section{Theory}

Radio programming provides benefits to listeners and advertisers. The production of radio broadcast signals entails only fixed costs. Additional persons may listen at no marginal cost, and listeners may not be excluded. ${ }^{7}$ Because radio signals are pure public goods, provision should occur when the sum of benefits across listeners and advertisers exceeds station operation costs. For optimal provision, stations should be added as long as the marginal benefits to listeners and advertisers exceed the marginal station's fixed costs. Actual entry occurs when advertising revenue exceeds the fixed costs of station operation. Because the programming service provided to listeners is unpriced, providers cannot capture any of its benefit as revenue. We expect this to lead to a failure of program provision in circumstances where a station cannot attract enough listeners to generate advertising revenue in excess of costs.

While we expect inefficient underprovision of unpopular programming, when advertising revenue to a format covers the costs of multiple stations in a market, it is also possible to get inefficient overprovision of broadcast services. ${ }^{8}$ A commercial provider enters as long as her station generates enough revenue to cover costs. Because listeners may be "stolen" from other commercial stations, the private benefits of entry overstate the social benefits. An extreme example illustrates this clearly. Suppose that 3 percent of the population listens to country music stations, regardless of how many country music stations are available. Suppose further that a city is large enough so that a listenership of 1 percent of the population generates sufficient revenue to cover costs. If programming offered by all country stations is identical, then (ignoring possible

\footnotetext{
${ }^{7}$ Radio and television broadcasting are very different in this regard. While cable technology makes television signals excludable, much radio listening occurs in cars, which cannot easily be cabled. ${ }^{8}$ See Mankiw and Whinston (1986) for a discussion of the possible inefficiency of free entry and Berry and Waldfogel (1996) for measurement of this inefficiency in commercial radio broadcasting.
} 
price-reducing effects of entry) the optimal number of stations is 1 . However, a single station will attract 3 percent of the population and earn profits, encouraging entry. The second and third entrants, who face private benefits from entry, generate no social benefits. Indeed, after they have entered, the benefits to listeners and advertisers are identical but costs have tripled.

Compared with optimal allocation of radio broadcasting, the market solution should have two characteristics. First, there can be an overprovision of popular programming, defined as programming in formats where advertising revenue can cover costs for at least one station. Second, there will be a failure to provide programming in formats where advertising revenue alone cannot support one station, even if the total benefit of the first station to advertisers and listeners exceeds costs.

Government has two possible roles correcting market failure in this environment. First, government can subsidize programming which, while worthwhile to provide, is not supplied by the market. That is, government can subsidize programming with benefits to listeners in excess of costs but which would not generate sufficient advertising revenue to finance its operations. Second, government can restrict excess entry into popular formats. This study is concerned with the former potential market failure. We identify possible areas of inefficent underprovision and ask whether public radio alleviates underprovision or displaces commercial provision.

\section{Data}

The basic data for this study are information on entry, programming format, and listening for stations in 165 major U.S. markets. Data for this study are drawn from a variety of sources. We obtain data on listening to commercial stations from Arbitron (1993), which reports average quarter hour $(\mathrm{AQH})$ listening for each commercial station in each of nearly $300 \mathrm{U} . \mathrm{S}$. markets during Spring 1993. AQH listening measures the number of persons listening for at least 5 minutes during an average quarter hour. The Arbitron data allow us to distinguish between stations broadcasting from within the metropolitan stations where they are heard (which we term 
"inside stations") and stations received in the metro area but broadcasting from elsewhere ("outside stations"). Duncan (1993) provides information on programming format for each commercial station. We use Duncan's classification to divide stations into 16 commercial formats. ${ }^{9}$ We use these two sources together to calculate both the number of stations broadcasting in each format in each market $(\mathrm{N})$ and the format's listening share (s) in the market. We calculate each of $\mathrm{N}$ and $\mathrm{s}$ by format separately for inside and outside stations. Duncan includes format information for 165 markets.

Our information on public radio comes from five separate sources. The Radio Research Consortium provided us with lists of public stations that in principle are receivable in each metro area. The Corporation for Public Broadcasting (CPB) provided a list of public stations receiving CPB support, along with each station's 1993 support by source. ${ }^{10}$ According to Mr. Young Lee of $\mathrm{CPB}, \mathrm{CPB}$-supported stations account for the vast majority of public listening. ${ }^{11}$ These are the stations we include as public stations in the study. National Public Radio (NPR) provided a file containing programming format information for each public station. We classify public stations into seven format groups, classical music, classical/news, jazz, jazz/news, news, other/news, and other. ${ }^{12}$ NPR also provided data on total listening to public stations, by market, for 88 markets in the sample. The public listening figure includes both inside and outside public stations. It also includes all public stations, not just those that are CPB-supported.

\footnotetext{
${ }^{9}$ The commercial 16 formats we use, based on Duncan's data are: adult contemporary, album oriented rock, black, big band/nostalgia, country, contemporary hit radio (top 40), classical music, classic album oriented rock, full service/variety, jazz, news/talk, oldies, religious, soft adult contemporary, Hispanic, and unknown.

${ }^{10}$ Major funding sources in the data include membership support, business underwriting, federal government, state and local government, and college support.

${ }^{11}$ A substantial number of noncommercial stations are not supported by CPB, but these are small, typically college stations.

${ }^{12}$ We classify a station as "classical" if its programming is more than 50 percent classical and less than 10 percent news (28 percent of CPB-supported stations), classical/news if more than 50 percent classical and more than 10 percent news ( 7 percent), jazz if more than 50 percent jazz and less than 10 percent news ( 7 percent), jazz/news if more than 50 percent jazz and more than 10 percent news ( 2 percent), other if more than 50 percent other and less than 10 percent news ( 29 percent), other/news if more than 50 percent other and more than 10 percent news (20 percent), and news if more than 50 percent news (6 percent). This classification is mutually exclusive.
} 
We use the information to create a cross section with the following information for each market: 1) number of inside stations by format for each commercial and public format, 2) number of outside stations by format for each commercial and public format, 3 ) inside listening (listening to inside stations), by format for each commercial format, 4) outside listening for each commercial format, 5) total public listening - unlike other data, which are available in all 165 markets, these are available for only 88 markets; and 6) revenue to inside public (CPB-supported) stations, by revenue source and public programming format, for each market. Finally, we have economic and demographic characteristics of each market, including population, average income, the distribution of education, and the number of colleges and universities. These are from Arbitron (1994) derived from Census data.

\section{Entry and the Size of the Market}

In this study we are concerned with possible market underprovision of broadcast services, as well as the possible displacement relationship between commercial and public stations. As a first step toward identifying possible areas of market underprovision this section describes the pattern of broadcast programming provided by the market. We also describe the pattern of public programming. We examine how commercial and public provision of radio broadcasting vary with the size of the market. In particular, we examine the relationship between two measures of programming provision, the number of stations in each format and the presence of stations in a format, and market size. We then examine the relationship between programming variety and listening.

\section{Market Size and the Number of Stations in Each Format}

Table 1 shows how the number of stations broadcasting from inside the metropolitan areas varies by population quintiles in the sample. With few exceptions, the number of stations in each format grows with market size. As one would expect, the number of commercial entrants grows 
with the size of potential audiences, and therefore advertising revenue. Markets in the first population quintile have an average of 11.33 commercial and 0.85 public stations, while the largest markets average 26.79 commercial and 2.21 public stations broadcasting from inside the metro area. Two notable exceptions to this pattern are commercial country music and the two public classical music formats, classical and classical/news. Both peak at the fourth, rather than the top, quintile. The number of stations varies substantially across markets of different sizes.

Table 1 also shows listening shares by format. On average 12.50 percent of persons are listening to local (inside-the-metro) radio stations for at least five minutes during any quarter hour. The vast majority ( 12.19 percentage points) listen to commercial stations, while 0.31 percentage points listen to public stations. Country music is by far the most popular commercial format, with 2.67 percent of the population listening, followed by album oriented rock ( 1.37 percent), contemporary hit radio ("top 40," 1.34 percent), and adult contemporary (1.26 percent). Commercial classical music and jazz stations attract 0.07 and 0.08 percent of the population as listeners, respectively. (These figures are averaged over markets with and without stations in each format. Format listening shares are higher when calculated only over markets where formats are present, particularly for formats available in relatively few markets).

\section{Market Size and Format Presence}

While the size of the market affects the number of firms entering the market, the number of stations in each format provides a poor measure of the extent of product variety available to consumers. Because stations within each format offer similar programming, consumers have similar listening options regardless of the number of stations in a format beyond the first.

Consequently, whether a market has a station in a format - "format presence" - provides a better measure of available product variety. Table 2 shows how format presence varies by market size for each commercial and public broadcasting format. The table also shows the average number of formats available in each market. 
The market provides a large amount of program variety in large markets. Of 16 commercial formats, markets in the largest population quintile have an average of 12.5 formats available inside the metro (13.3 including stations broadcasting from outside the metro). By contrast, markets in the smallest population quintile have an average of only 8.2 inside formats (9.6 including the outside stations). All but four formats (classical, full service/variety, jazz, and Hispanic) are provided by the market in over three quarters of the largest markets. Of the 32 markets in the sample with populations that are over 10 percent Hispanic, 31 have in-metro Hispanic stations.

The smallest population quintile includes metropolitan areas with fewer than 246,000 persons. Of the 33 markets in this population range, the market provides classical and jazz programming in two cities each and classic album oriented rock programming in three. Public stations provide classical music in 11, and jazz in 5, of the 33 smallest markets. The second smallest population quintile includes 33 markets with populations between 246,000 and 364,000 . None of these markets has a commercial classical station, and only two have a commercial jazz station. Ten of these markets have a public classical station, and four have a public jazz station. In the middle population quintile of markets, including the 32 markets with population between 364,000 and 561,000, commercial stations provide classical and jazz programming each in three cities while public stations provide classical programming in ten cities and jazz in two. The fourth population quintile includes 34 cities with populations between 561,000 and 1,198,000. The market provides classical programming in four markets and jazz programming in eight, while public stations provide classical music programming in 26 and jazz in nine. Only in the top quintile, including cities over 1,198,000 persons, is commercial provision of classical music programming more prevalent than public provision. Commercial stations provide classical programming in 19 of the 33 largest markets, compared with only 12 served by public stations. Public stations provide jazz programming in 17 of these cities, compared with 14 served by commercial jazz stations. 
Table 2 clearly shows the areas of possible inefficient underprovision. Six formats are provided by the market substantially less frequently than the other ten: classical music, jazz, classic album oriented rock, and soft adult contemporary, as well as black and Hispanic formats. These formats are provided by the market especially infrequently in small markets. There are commercial classical and jazz stations inside of only 5 and 7 markets among the roughly 100 cities in the three smallest population quintiles, respectively.

Two questions come to mind as one examines tables 1 and 2 . First, does the market fail to provide programming with total value in excess of its costs? Commercial classical provision, for example, is common in the largest markets but substantially less common in the fourth population quintile. One can infer that there is some level of population (in the range of quintiles 4 and 5) allowing a commercial classical station to attract enough listeners to cover costs with advertising revenue. As population dips below the implied breakeven level, stations cannot be financed with advertising revenue alone. However, if programming has any value to listeners, for the range of market sizes just below the largest, the total value of (nonexistent) commercial classical programming would exceed the cost of provision. If programming has substantial value to listeners, many markets should have classical stations.

Outside of the top population quintile, commercial stations provide classical programming in only 9 (of 132) markets. The public sector, by contrast, provides classical programming in nearly half (57) of these cities outside the largest quintile. Of the 69 markets outside the top two quintiles not served by public classical stations, only 4 have commercial classical stations broadcasting from inside the metro. Because such markets have no public stations, it is not possible that public provision is displacing commercial entry. Rather, commercial entry in such markets is presumably not viable. That is, a lone commercial station cannot cover its costs with advertising revenue. As we move to the third and fourth population quintiles, commercial entry becomes slightly more common and public provision becomes widespread. 
Second, is there a relationship between commercial and public provision in related formats? Commercial and public classical provision appear related. Commercial provision is rare in cities smaller than those in the top quintile and jumps substantially in the largest cities. Public provision, by contrast rises slowly across market sizes until the top quintile, when it falls, perhaps because of the prevalence of commercial provision. Moreover, does the presence of public stations induce the absence of commercial stations in related formats? We return to this question in section 5 below.

\section{Listening and Product Variety}

We care about the amount of program variety only if it has value to listeners. Although we cannot measure the value of variety to listeners, this section examines the relationship between program variety in a market and listening. If variety is valuable to listeners, then we expect to observe a larger fraction of the population listening in markets with greater programming variety. ${ }^{13}$

Our data set includes information on the numbers of inside and outside stations broadcasting in 23 distinct programming formats, 16 commercial and 7 public. A crude but natural way of measuring the product variety available in a market is simply the number of different formats available. We have commercial listening shares for 165 markets. Of these we have public listening shares for 88 markets. Consequently, we examine the relationship between variety and listening in two different ways. For the 88 markets with total $($ commercial + public) listening data, we examine the relationship between total listening and the number of commercial and public formats available inside or outside the metro. Figure 1 plots average listening shares as a function of the number of formats available and shows a clear positive relationship. Markets

${ }^{13}$ Even if program variety does not attract additional listeners, it may be valuable to existing listeners by allowing them to listen to more preferred programming. 
with 10-15 public and commercial formats available have listening shares of 15 to 16 percent, while markets with 16 formats or more have listening shares of 17 to 21 percent

Figure 2 examines the relationship between commercial listening and the number of commercial formats available (from inside or outside the metro) for all 165 markets. This figure confirms the positive relationship between format availability and listening. The positive relationships in figures 1 and 2 may not demonstrate positive impacts of variety on listening. Rather, they may reflect endogeneity in the number of available formats. It is possible that more varieties of stations enter the market in metropolitan areas with greater tastes for variety. To measure the impact of variety on listening, we need a source of exogenous variation in variety, which we find in population. The larger is a metropolitan area's population, the more stations it can support. Even if tastes are identical in metro areas of differing populations, the number of stations (and formats available) will differ. Hence, population is a suitable instrument for the number of varieties.

When we regress the overall listening share on the number of varieties available we find a strong positive relationship: each additional available format adds 0.003 points to listening (see table 3). When we instrument for the number of varieties using population, we find a stronger relationship: each additional variety adds 0.0062 points of listening. We obtain similar results when we regress commercial listening on the number of commercial formats available. We conclude that variety attracts listeners and is therefore valuable. As a result, there is some reason to be concerned about the market's failure to provide as much programming variety in small areas as it does in large areas.

\section{The Relationship between Commercial and Public Provision: Crowding Out?}


The main programming formats offered by CPB-supported public stations are news, classical music, and jazz. Other programming provided by public stations includes folk music, world music, pop music, and eclectic music. ${ }^{14}$ The three main formats provided by public stations, news, classical, and jazz, appear by their names to be similar to the three similarly named commercial formats. This section explores whether public and commercial programming appear to be substitutes and whether they appear to displace each other.

We recognize that commercial and public stations within a format are not identical. Indeed, unless they simultaneously broadcast the same programming, no two stations are identical. However, some stations are more similar than others. To see this clearly, consider an extreme hypothetical situation with two top 40 stations broadcasting identical programming but at different times. The second stations offers listeners a distinct benefit because, at any given moment, it may broadcast a song preferred by some listeners. The extent of distinct benefit offered by the second station in the hypothetical example is likely to be small. If stations are similar, this similarity will have observable implications. Identical stations will simply split a market by "stealing" listeners from one another. Thus, the presence of additional stations with similar programming will reduce listening at the first station. By contrast, two stations offering distinct programming - and drawing different types of listeners - will be less likely to draw each others' listeners. The presence of a second, dissimilar station will not be associated with a reduction in listening at a first station.

Using this logic we attempt in this section to measure the similarity of public and commercial programming in three formats (classical, jazz, and news). While public and commercial stations are surely not identical within each of these formats, we appeal to the data to 
indicate the extent to which public and commercial stations draw the same listeners. We have two approaches to studying the extent of substitutability between commercial and public programming. First, we examine the relationship between commercial and public station presence and commercial listening. Does the presence of a public classical station, for example, reduce a local commercial classical station's listening share? We do not have format-level public station listening data, so we cannot perform the analogous reverse exercise. However, we do have format-level revenue data for public stations. Consequently, our second approach to this question is to measure the impact of public and commercial stations on public station listener-related revenue (from members and business underwriters). If we find strong negative relationships - if public stations reduce commercial listening, if commercial stations reduce public listener-based revenue - we will infer that public and commercial programming are similar. In addition, we study possible crowding out directly by measuring the direct relationship between public and commercial station presence.

\section{Public Station Presence and Commercial Listening}

If public and commercial programming are close substitutes, then the presence of a public station in a similar format will draw listeners from commercial stations. To test for this we regress commercial listening, by format (for classical, jazz, and news/talk), on a constant, the number of inside commercial stations in the format, the number of outside commercial stations in the format, the number of inside public stations in the format, and the number of outside public stations in the format. We also report specifications that with additional market characteristics, including the percent black and Hispanic, the percent college educated, per-capita income, and region dummies. For these regressions and those that follow, public classical includes both public classical and public classical/news formats, public jazz includes both jazz and jazz/news formats, 
and public news includes both public news, classical/news, jazz/news, and other/news. ${ }^{15}$ Two of the hybrid categories appear in more than one category. For these regressions we include only markets with commercial listening in the format (therefore we include only markets with either inside or outside commercial stations in the format).

Results, in table 4, show that commercial listening increases significantly in the number of inside and, to a lesser extent, outside commercial stations in the format. The number of inside public stations is negatively related to the commercial listening share, but the relationship is consistently significant only for classical. When the market characteristics are included, there is a nearly significant negative relationship in the news/talk format. Each inside commercial classical station increases commercial classical listening by 0.2 to 0.25 percentage points, and each inside public classical station reduces commercial classical listening by 0.09 to 0.15 percentage points. The average public station's listening share is between 0.2 and 0.4 percent of the population. ${ }^{16}$ Hence, while there appears to be some substitutability of commercial and public classical programming, public classical listeners cannot all be drawn from commercial stations.

The evidence on listening suggests that commercial and public classical stations are substitutes, at least to some degree. The general absence of statistically significant relationships between public presence and commercial listening in the other two formats suggests that public and commercial programming in these formats attract distinct audiences and, by extension, that programming in jazz and news are less similar across the public-commercial divide.

\section{Public and Commercial Station Presence and Public Station Revenue}

\footnotetext{
15 Including both straight classical, jazz, or news and hybrid (for example classical/news) stations in our measure of the number of public stations exacerbates the general problem that public and commercial stations in a format may offer different programming. To the extent that we group unlike prograinming with straight programming within a format, we introduce measurement error in the true number of public stations in a format. This will bias our procedure away from finding any displacement.

16 We can compute this only approximately because, while we separately observe the numbers of public stations broadcasting from inside and outside the metro areas, we only observe total public listening. The average public listening share per inside (total) public station is $0.4(0.2)$ percent.
} 
If public and commercial stations have similar programming, then the presence of commercial stations will draw not only listeners but also listening-based contributions from public stations. We define listener-based contributions as those from members, whose contributions reflect valuation of the programming, and revenues from business and foundation underwriters, which, like advertising revenue, also depend on audience sizes.

Our revenue measure is per-capita listener based revenue (to inside stations in this format) per station in this format. We regress this on the number of inside public stations beyond the first, the number of outside public stations, the numbers of inside and outside commercial stations, per capita income, and the percent of college graduates in the population. We include in the samples only markets with inside public stations in the format. Results in table 5 show that public station revenue declines with the number of commercial stations in the format for each of the three formats. However, the decline is (marginally) significant only for classical music. Table 5 also shows that per-station revenue declines in the number of inside public stations. However, the variable, "Inside Public Stations beyond the First" is positive for only a handful of observations for the classical, jazz, and news samples, so should not be taken too seriously.

Taken with the relationship between public stations and commercial listening, this result reinforces the idea that commercial and public classical stations offer substitute programming. The absence of significant relationships for jazz and news again suggests that public and commercial stations in these formats attract distinct audiences.

\section{Do Public Stations Crowd Out Commercial Stations?}

We can examine the possible displacement of commercial stations by public stations directly by regressing the number of commercial stations in a market on its market determinants (population, income, and other controls) along with the number of public stations in the format. Casual examination of the pattern of commercial and public provision above suggests that the scope for commercial-public displacement varies by market size. If commercial classical stations 
are not viable in markets outside the top two quintiles when operating without public competition, then they will not be displaced by public entry in those markets. Hence, we allow the relationship between public and commercial stations to vary by population quintile. Table 6 presents these regression results for three formats where commercial and public provision seem most likely to interact, classical music, jazz, and news. Given the apparent substitutability of public and commercial classical programming documented above, we expect the strongest displacement effects (if we find any) in classical music.

The number of commercial classical stations broadcasting from within a metro area depends strongly and positively on population (although the effect of population declines as population increases) and negatively on the number of commercial classical stations receivable in the metro area but broadcasting from elsewhere. Each outside-the-metro commercial classical station reduces inside classical presence by 0.21 stations. As expected, the effect of local public classical stations varies by market size. In the three smallest market quintiles the number of public classical stations bears no significant relationship to the number of classical stations provided by the market. Public entry bears a significant negative relationship to commercial entry in the largest markets, however. In the fourth quintile each public classical station is associated with a 0.2 station reduction in the number of commercial stations (with a standard error on 0.06 ), and in the top quintile each public classical station reduces commercial entry by 0.5 stations $(0.10)$.

If we view public entry as exogenous, then the estimated relationships between the numbers of public and commercial stations reflect the causal impacts. In the largest markets, for example, these estimates indicate that each additional public classical station reduces commercial classical entry by half a station. Consequently, an additional public station in a market in the largest quintile raises the total number of classical stations in a market by one half. Public entry in markets outside the top two population quintiles has no effect on commercial entry. Rather than cannibalizing commercial stations, such entry goes straight toward providing services that the 
market does not provide. Public entry outside the largest markets adds to the total number of public stations without displacing any commercial stations.

Results for jazz are rather similar, although the apparent displacement effect is weaker. As in classical, there is no significant displacement relationship in the bottom three market quintiles. In the next-to-largest quintile, each additional public jazz station is associated with a reduction in commercial jazz entry by 0.19 stations (with a standard error of 0.15 ). In the top quintile each additional public jazz station is associated with a reduction in commercial jazz entry by $0.29(0.15)$. Column 3 of table 6 provides for results for the relationship between public news and commercial news/talk. There is no clear pattern of displacement. This is perhaps to be expected, given the differences between programming on the two types of stations. Public news consists largely of the news-oriented National Public Radio programs "Morning Edition" and "All Things Considered," while commercial news/talk includes a large talk component.

The number of commercial classical stations may be endogenously determined with the number of commercial stations. It is difficult to find suitable instruments for the number of public stations - variables affecting the number of public stations that do not also determine the number of commercial stations. ${ }^{17}$ Short of finding suitable instruments we can make an intuitive argument about the likely direction of bias in the OLS estimates. It seems likely that the numbers of both commercial and public stations depend positively on "tastes for radio." Markets with strong tastes for radio will have more public and more commercial stations, biasing OLS away from a finding of displacement of commercial by public stations. From this perspective, the OLS estimates underestimate the true impact of public stations on commercial stations. ${ }^{18}$

\footnotetext{
${ }^{17}$ We experimented with a number of possible instruments, including the number of colleges and universities and the numbers of college educated persons. While some of these variables were significantly related to the number of public stations, the resulting IV estimates of the effect of public stations of commercial stations were very imprecise.

${ }^{18}$ It is also possible that markets differ not in their tastes for radio overall but in their tastes for public (or commercial) radio. Then markets with more public stations would have fewer commercial stations (per capita) without displacement. Given that commercial and public stations carry similar programming (for example
} 


\section{The Commercial Response to an Absence of Public Classical and Jazz Stations}

Given the evidence of a displacement relationship between public and commercial stations in classical music and, to a lesser extent, in the jazz format, it is interesting to estimate the impact of a hypothetical absence of public funding on the commercial provision of broadcasting services. Such an exercise requires a model of public station revenue - allowing determination of the number of public stations that could subsist without government subsidies - and is beyond the scope of this paper. However, we can simply pose a related question: How many markets would be served by classical music and jazz stations in the absence of public stations? ${ }^{19}$ This is not meant as a simulation of a plausible policy. Rather, because much public radio broadcasting would continue in the absence of government support, this exercise provides a lower-bound estimate of the extent of service that would be available if government subsidies to public broadcasting were eliminated. Furthermore, because commercial and public programming within a format are not identical, we note at the outset that the number of markets served by any programming in the format provides an incomplete measure of programming availability.

To perform this exercise, we estimate separate probit models on commercial classical and jazz presence with the number of public commercial and jazz stations, respectively, on the righthand side along with other stations determinants such as population. These probits are reported in table 7. We allow the impact of public stations on commercial presence to vary for the top two

classical music and jazz), it seems unlikely that variation in tastes for public radio induces the apparent displacement.

19 In addition, if endogeneity of public stations biases the coefficients away from a finding of displacement, then simulations of the elimination of public stations will underestimate the extent of commercial offset of withdrawal of public programming 
population quintiles for classical music. Jazz coefficients do not vary by population quintile in this specification.

We simulate the models both with actual numbers of public stations and with no public stations (in conjunction with actual values of other right-hand side variables). We refer to these as "default" and "no public" simulations. We calculate the number of markets served in the absence of public stations as follows: We assume that all markets currently served by commercial stations would remain served by commercial stations in the absence of public stations. We then add the markets which are served under the no public simulation but neither in reality nor under the default simulation. ${ }^{20}$ We compare these simulated numbers of markets served with the numbers actually currently served by either public or commercial stations.

Table 8 indicates that 88 of 165 markets are currently served by either public or commercial classical stations (or both). Of these, 68 are served by public classical stations; 28 are served by commercial classical stations ( 8 markets are served by both types). If public stations were eliminated, 60 markets served exclusively by public classical stations would lose access to classical programming. In exchange, commercial stations would enter 10 markets not currently served by commercial stations, and 38 markets would have classical music programming.

While the market would not offset much of the loss of public stations, the offset measured solely by whether a market is served by any classical station - is substantial in large markets, especially for classical music. Currently, 26 of the largest 32 markets are served by either commercial or public classical stations. Of these 26,12 are served by public stations, and 19 by commercial stations ( 5 by both). In the absence of public classical stations, commercial firms would continue to serve the 19 markets they already serve and enter an additional 7 
markets. In the top population quintile, the same number of markets currently receiving either public or commercial classical music would receive commercial classical programming in the absence of public broadcasting. If all commercial and public classical programming were identical, then one could say that listeners in markets in the top quintile would be as well off in the absence of public broadcasting. While commercial and public classical programming appear (based on evidence above) to be more similar than commercial and public programming in jazz and news, they are clearly not identical. Hence, while there is a full quantitative offset (the same number of markets receives classical programming in the absence of public broadcasting), there is not necessarily a full qualitative offset (listeners will not necessarily be as well off). Furthermore, in markets below the top quintile, even the quantitative commercial offset shrinks substantially. In the absence of current public stations in markets below the top two population quintiles, there is no additional commercial entry.

Currently, 29 of the largest 32 markets have commercial or public jazz programming. Sixteen of these markets are served by public jazz stations and 13 other markets have commercial jazz stations. In the absence of public jazz stations, 16 markets would have commercial jazz stations. Thus, the loss of public service in 16 markets would be only partially quantitatively offset by entry of commercial jazz service in three markets. There is no commercial jazz entry offsetting the simulated absence of public jazz stations outside the top population quintile.

Depending on the similarity of commercial and public programming, the simulation results in table 8 can raise questions about funding public broadcasting in the largest markets, particularly for classical music programming. If public and commercial classical programming were identical, and if the same number of large markets receive classical programming with or without public

\footnotetext{
${ }^{20}$ We predict that a market has commercial service if the probit prediction exceeds 50 pecent.
} 
broadcasting, then government funds would obviously be wasted providing classical programming in those markets. On the other hand, if public and commercial programming are sufficiently different so that the distinct benefit of public classical programming to its listeners, beyond the benefit of commercial classical programming, exceeds its cost of provision, public funding of classical music - even if it crowds out commercial classical programming - may not we wasteful.

Results in table 8 also clearly show that, in the absence of public broadcasting, persons living outside the largest markets would receive very little classical music or jazz programming. While we cannot say whether such programming has value to listeners in excess of its costs - and therefore whether its provision actually corrects market failure - its provision is also not clearly wasteful. That is, public provision of jazz and classical programming outside the largest markets is not duplicative of commercial service that would be provided in its absence.

\section{Does Public Funding Correct Underprovision or Displace Commercial Programming?}

Results in the previous section indicate that public entry in classical and, to some extent jazz, displaces commercial entry in large markets. Given this effect we can examine the pattern of government support for public radio across markets - according to their actual or simulated commercial format presence - to roughly assess how public broadcast provision is divided between displacing commercial entry and providing programming in areas where the market would not. In the latter case it is at least possible that public provision corrects inefficient underprovision. If commercial and public programming were identical within classical and jazz formats, these calculations would provide a measure of wastefulness of public broadcast funding. Because commercial and public programming are not identical, these calculations show the amount of funding supporting public broadcasting similar to programming that the market would provide in its absence. 
Of their overall 1993 operating budgets of $\$ 391.6$ million, CPB-supported public stations received 40 percent of their income from government sources (see table 9). Most of the government support is from state, rather than federal or local sources, with the largest component (14.9 percent) from public colleges. The CPB provided 13.7 percent ( $\$ 53.7$ million) of these stations' operating budgets. The bulk of the remainder of the stations' funds is provided by listeners (24.1 percent) and business underwriting (17.3 percent).

Of $\$ 32.9$ million in federal, state, and local government support for public classical (including classical/news) stations, 82 percent was allocated to stations in markets without a commercial classical station. Thus the vast majority of public funding to classical stations is not obviously duplicative of what commercial stations already offer. Because public classical stations appear to displace commercial classical entry, particularly in large markets, the amount of public funding allocated to markets without current commercial presence understates the amount of public support for programming similar to programming the market would provide in its absence. Slightly over a third (38 percent) of government support for public classical stations is allocated to stations in markets that the simulations indicate would receive commercial classical programming in the absence of public classical programming. Thus, 38 percent of public funding supports classical programming that is similar to programming that market would provide in its absence.

Of the $\$ 15.5$ million in government support for public jazz (including jazz/news) stations, 64 percent was allocated to stations in markets without a commercial jazz station. Because of the weak negative relationship between public and commercial stations in jazz, nearly all of the public support to jazz stations ( 57 of the 64 percent) is allocated to stations in markets that receive no commercial jazz programming even in the "no public jazz" simulations. However, 43 percent of public funding to jazz stations supports programming similar to programming that commercial stations would offer in their absence. Recall, however, that although we find a direct 
displacement effect of public jazz stations on commercial jazz stations, we found no other evidence of jazz programming substitutability above. Because we find no evidence of substitutability of public and commercial news programming, there is no evidence that any public funding of news programming supports duplication of programming that the market would provide in its absence.

While the majority of public funds subsidizing radio broadcasting are allocated to stations in markets with no commercial competition in their formats, the pattern varies substantially by quintile and format. Table 10 provides a more detailed picture of public support for public classical and jazz stations, by population quintile and by whether they have commercial competition. Table 10 confirms that the majority of public funds go to stations without commercial competition. For example, in the bottom three population quintiles, total government support for public classical and jazz stations in markets with commercial competition is under $\$ 500,000$. One potentially curious pattern in table 10 , however, is the relatively large amount of government support for jazz and classical stations without commercial competition in markets in the top quintile. Nearly a sixth (15.4 percent) of government subsidies to public classical music stations are given to large-market (quintile 5) stations with commercial competition. Largemarket (quintile 5) public jazz stations with commercial competition receive over a third of government subsidies to jazz stations. If public jazz stations air programming similar to commercial jazz programming, it is unlikely that support of large-market public jazz stations will alleviate an inefficient underprovision problem.

The extent of potentially duplicative public support in large markets is exacerbated when we look at funding by whether markets are simulated to receive commercial service in the absence 
of public programming. Large (quintile 5) markets that are simulated to receive commercial classical programming in the absence of public classical stations receive a third of government subsidies to public classical stations. Public jazz stations in large (quintile 5) markets simulated to have commercial jazz even in the absence of public jazz stations receive 42 percent of government funding to public jazz stations.

We must emphasize, however, that to draw an inference from the evidence presented here that public programming wastefully duplicates commercial provision requires an assumption that public and commercial programming are identical within format. While we have offered some evidence that commercial and public classical and jazz stations are at least somewhat substitutable for one another, we have not demonstrated that they offer listeners identical benefits. In the absence of direct evidence on the similarity of their programming, we cannot label as "wasteful" government funding of public stations with commercial competition.

\section{Conclusion}

This study has examined provision of radio broadcasting services by the market in the U.S., along with the pattern of public radio. Although the market provides most broadcast formats in most markets, some formats - notably classical music and jazz - are provided less frequently by the market. We examine the interaction between commercial and public provision of broadcast services in classical music, jazz, and music, and we find evidence of substitutability of commercial and public programming in jazz, and especially classical music. Furthermore, public entry appears to displace commercial entry in large markets. Although the bulk of government support for broadcasting goes to public stations in markets without commercial competition, over 
a third of public funding of stations airing jazz and classical music programming is allocated to public stations in the markets which would be served by similar commercial programming in the absence of public broadcasting.

Arguments in this paper cannot demonstrate whether public funding of radio broadcasting is wasteful. Rather, we focus attention on the degree of similarity of commercial and public programming. We find evidence of substitutability in classical music programming and evidence of displacement in both classical music and jazz. By itself this does not demonstrate that public funding that displaces commercial programming in these categories is unjustified. Whether public funding of programming that displaces similar commercial programming is justified depends on the degree of similarity between public and commercial programming.

It is important to note that the results of this study do not necessarily imply that funding of public radio should be reduced. This study has examined the allocation of the current public radio budget across markets. The determination of the correct size of the public radio budget is outside the scope of this study. Even if it were true that some public radio funding should be withdrawn from some large markets, it is entirely possible more funding should be allocated to public radio in other markets. Such a determination requires information, that we currently lack, on the value of public broadcasting to its listeners in those markets.

While this study has documented many empirical regularities, the descriptive estimates we have presented do not allow us to realistically model the impact of public subsidies on available programming. The next step planned for this research is the development of realistic structural models of commercial and public entry and revenue, allowing simulation of alternative government funding policies. 


\section{References}

The Arbitron Company, Radio Metro Market Guide, 1993-1994. New York: The Arbitron Company, 1994.

The Arbitron Company, Radio USA, Spring 1993. New York: The Arbitron Company, 1993.

Berry Steven T. and Joel Waldfogel. "Free Entry and Social Inefficiency in Radio Broadcasting." NBER working paper 5528, April 1996.

Bradford, David F. and George G. Hildebrandt. "Observable Preferences for Public Goods." Journal of Public Economics 8, no. 2 (October 1977):111-131.

Corporation for Public Broadcasting. Public Radio: Fiscal Year 1993 Programming. Washington: CPB. December 1994.

Cutler, David M. and Jonathan Gruber. “Does Public Insurance Crowd Out Private Insurance?” Quarterly Journal of Economics 111, no. 2 (May 1996): 391-430.

De Witt, Karen. "Gingrich Foresees a World without Public Broadcasting.” New York Times. December 6, 1994. Sect. 1, page 9.

Duncan, James H. American Radio, Spring 1993. Indianapolis: Duncan's American Radio, August 1993.

Duncan, James H. Duncan's Radio Market Guide, 1994 Edition. Indianapolis: Duncan's American Radio, January 1994. 
Head, Sydney W. World broadcasting systems : a comparative analysis. Belmont, California: Wadsworth Publishing Company. 1985.

Mankiw, N. Gregory and Michael D. Whinston. "Free Entry and Social Inefficiency." RAND Journal of Economics 17, no. 1 (Spring 1986):48-58.

Samuelson, Paul A. "The Pure Theory of Public Expenditures." Review of Economics and Statistics 36 (1954):387-389. 


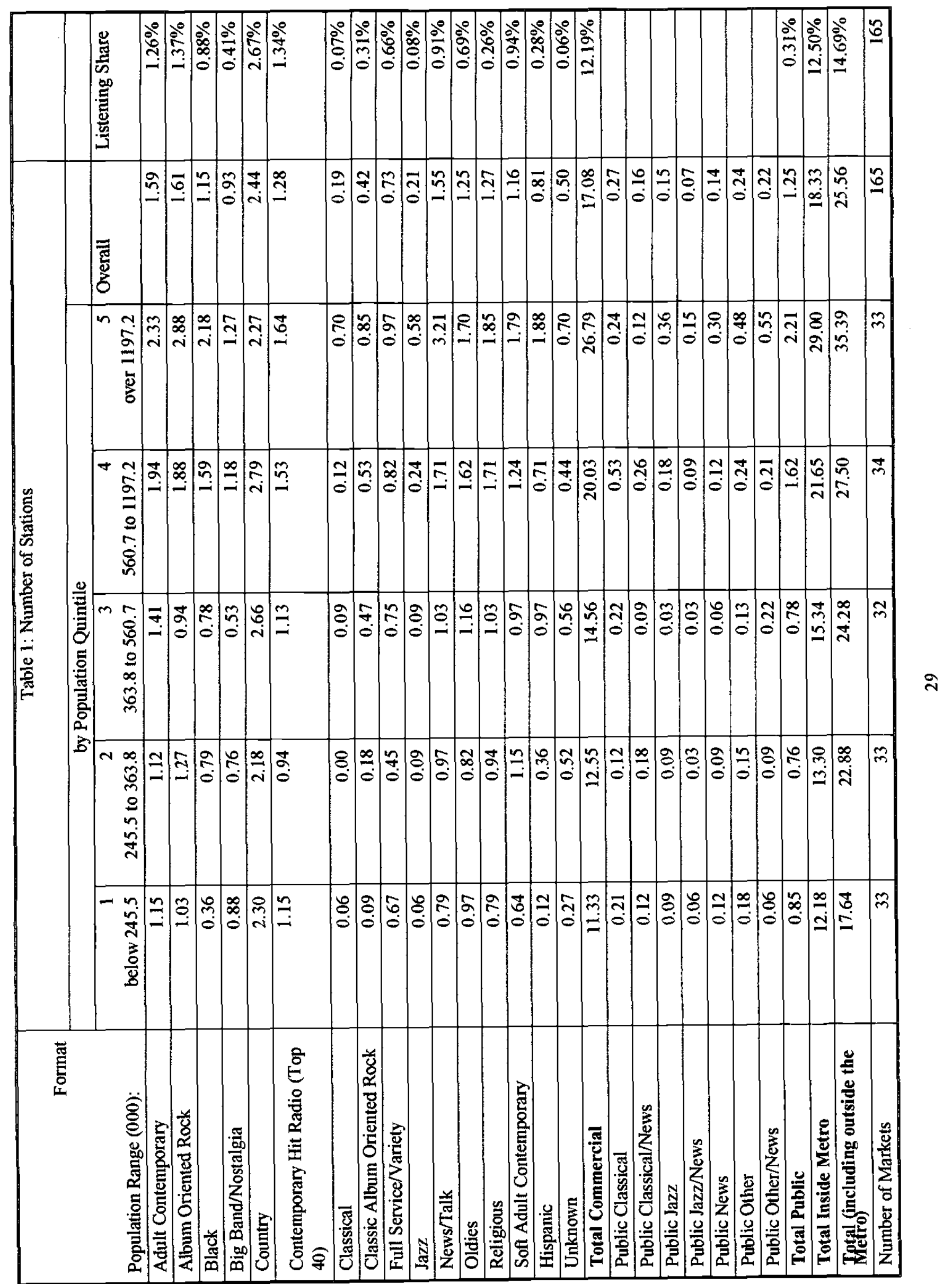




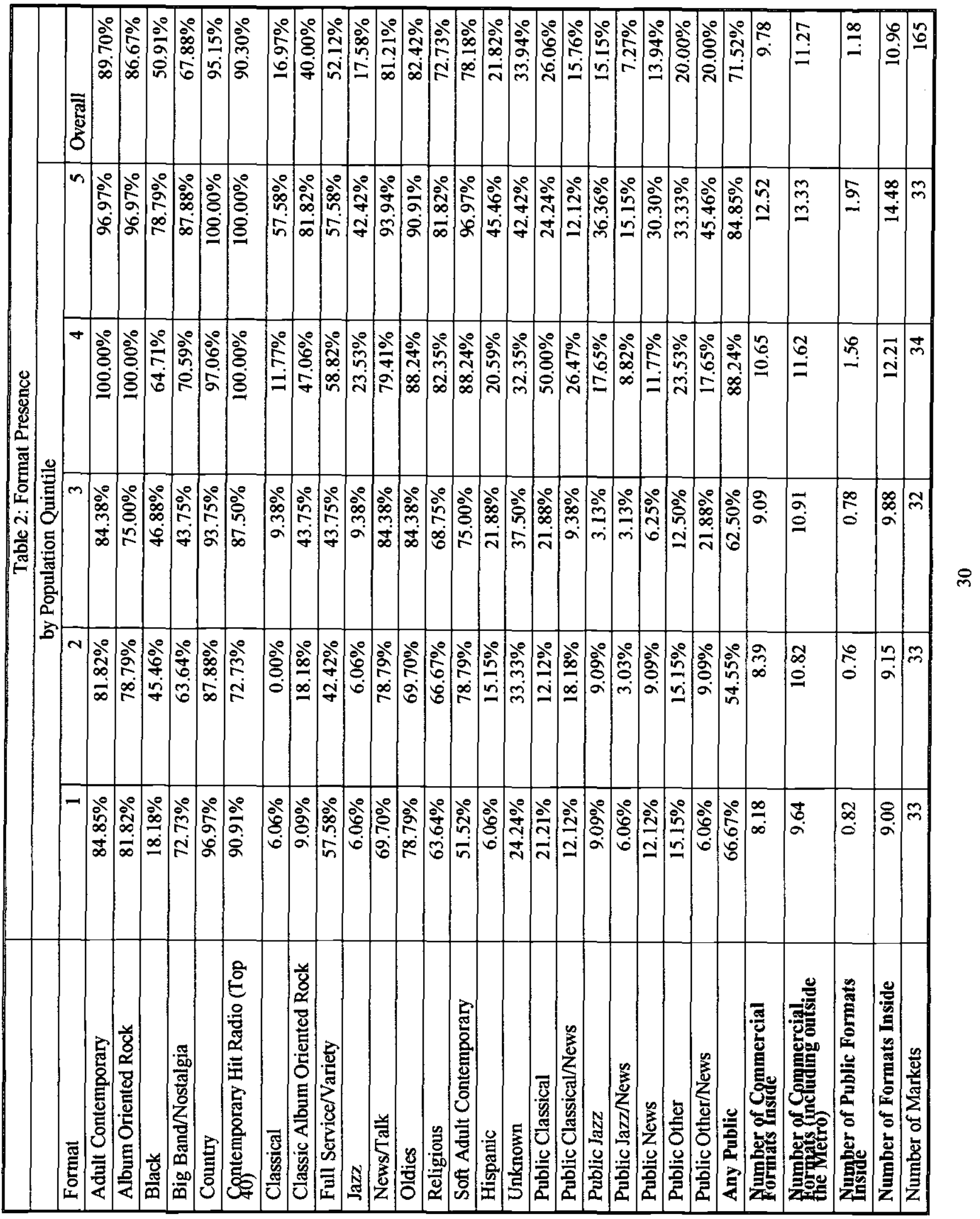




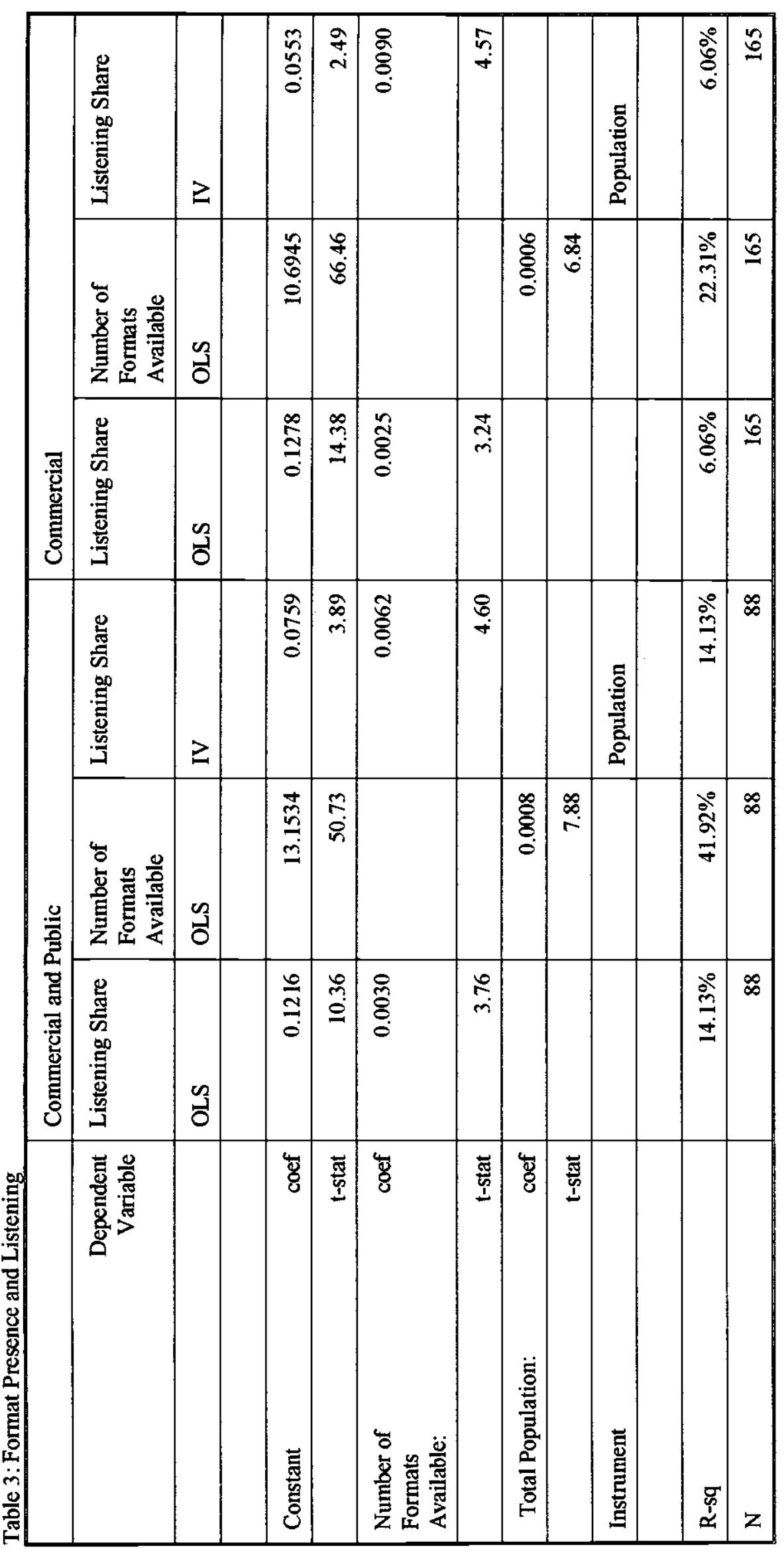




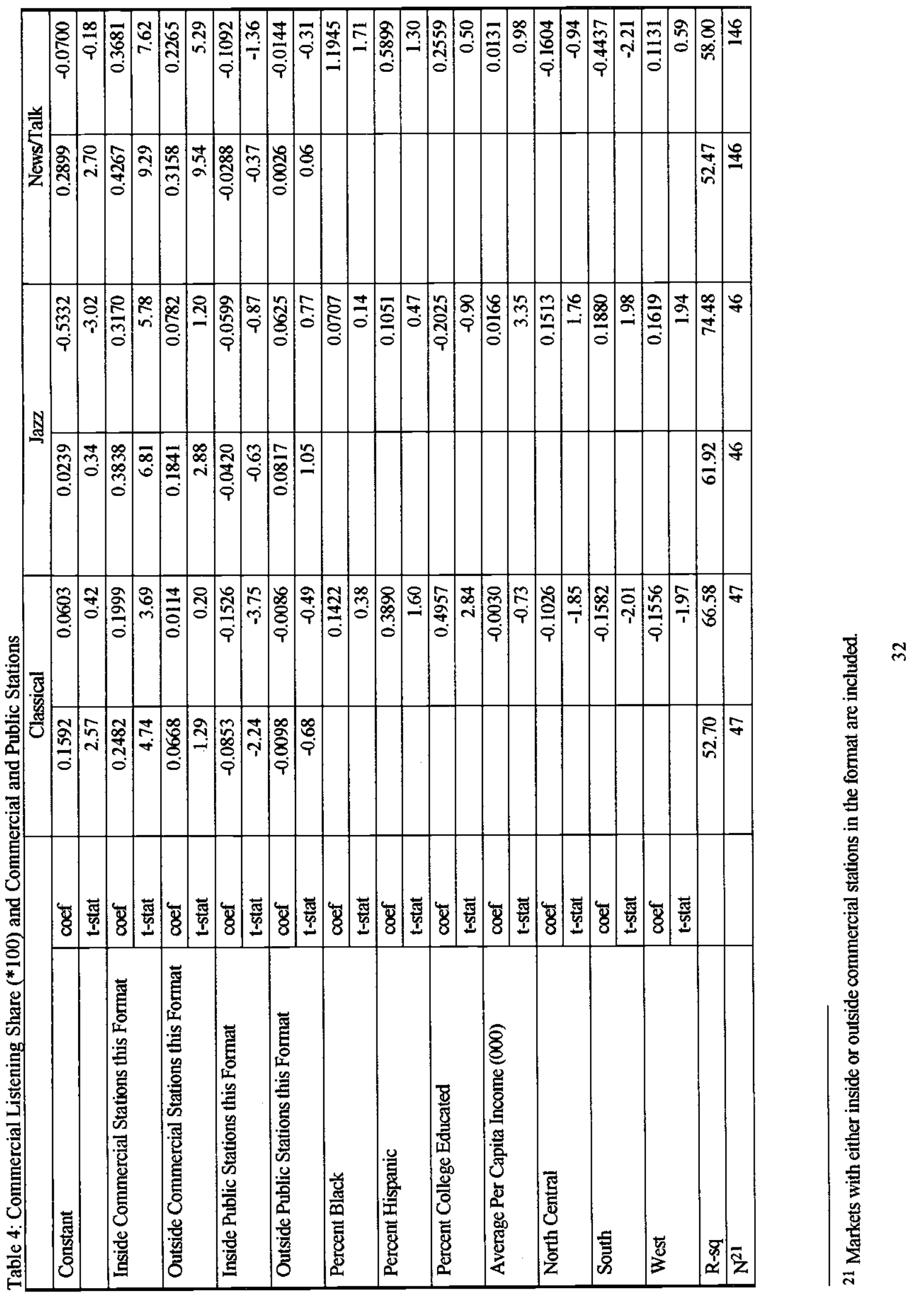




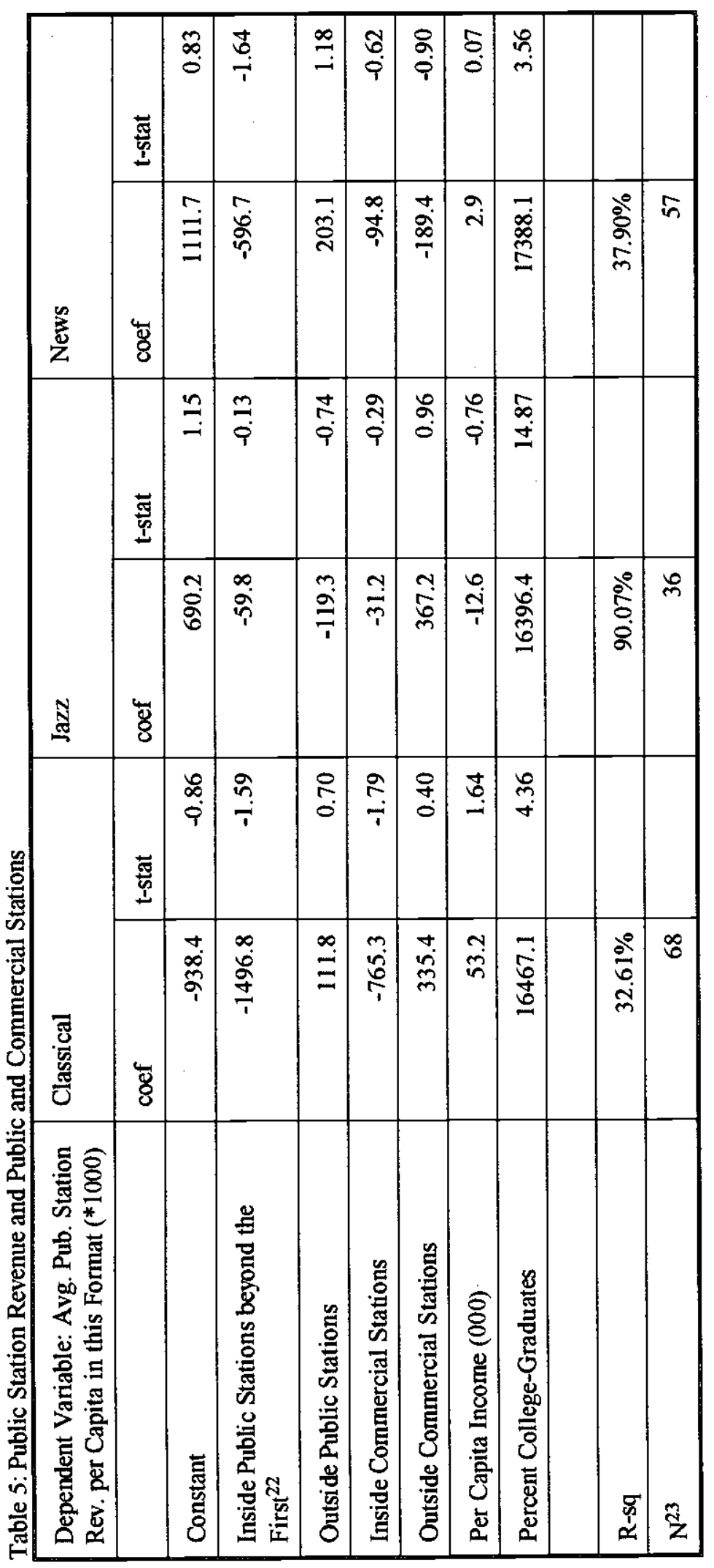




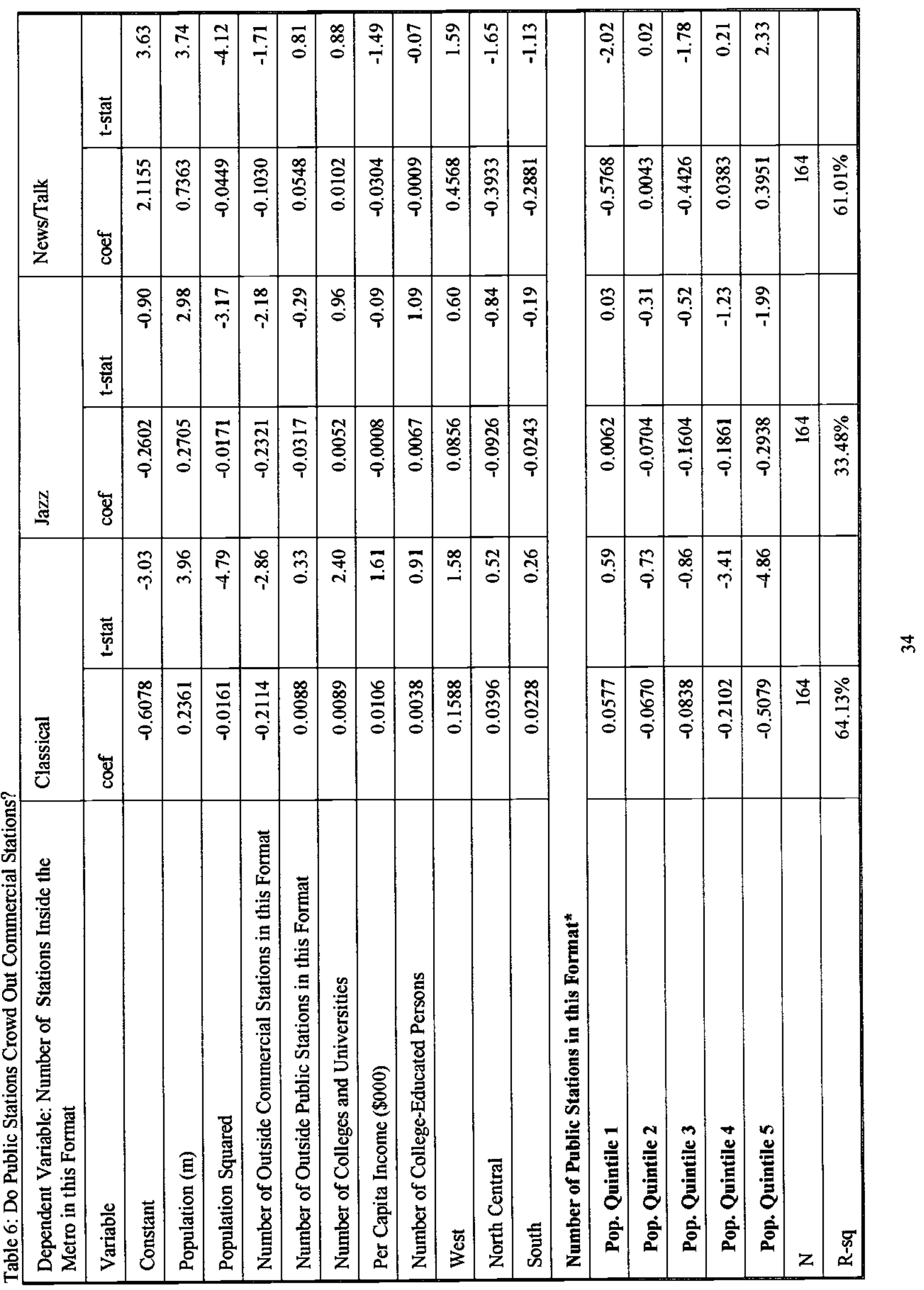




\begin{tabular}{|c|c|c|c|c|}
\hline & \multicolumn{2}{|l|}{ Classical } & \multicolumn{2}{|l|}{ Jazz } \\
\hline & coef & t-stat & coef & t-stat \\
\hline Constant & -5.6506 & -3.23 & -3.4335 & -2.65 \\
\hline Total Population (millions) & 1.3534 & 1.38 & 3.0919 & 2.37 \\
\hline Population Squared & $-1.77 e-05$ & -0.04 & $-1.69 e-03$ & -1.90 \\
\hline Population Cubed & $-2.99 \mathrm{e}-09$ & -0.11 & $2.94 \mathrm{e}-07$ & 1.79 \\
\hline $\begin{array}{l}\text { Number of Outside Commercial } \\
\text { Stations }\end{array}$ & -1.9058 & -2.18 & & \\
\hline $\begin{array}{l}\text { Number of Outside Public } \\
\text { Stations in this Format }\end{array}$ & 0.0074 & 0.04 & -0.0446 & -0.09 \\
\hline Per Capita Income $(000)$ & 0.0595 & 1.25 & -0.0324 & -0.95 \\
\hline $\begin{array}{l}\text { Number of College-Educated } \\
\text { Persons }\end{array}$ & 0.0322 & 0.96 & 0.0575 & 2.18 \\
\hline \multicolumn{5}{|l|}{ Region Dummies: } \\
\hline West & 0.7351 & 1.00 & -0.4664 & -0.89 \\
\hline North Central & 0.2342 & 0.39 & -0.6913 & -1.43 \\
\hline South & -0.0969 & -0.13 & -0.3610 & -0.77 \\
\hline $\begin{array}{l}\text { Number of Public Stations in } \\
\text { this Format }\end{array}$ & & & -0.7452 & -1.99 \\
\hline \multicolumn{5}{|c|}{ Number of Public Stations in this Format } \\
\hline $\begin{array}{l}\text { x Bottom three Population } \\
\text { Quintiles }\end{array}$ & -0.2824 & -0.48 & & \\
\hline x Quintile 4 & -0.8088 & -1.63 & & \\
\hline x Quintile 5 & -2.1000 & -2.75 & & \\
\hline $\mathrm{N}$ & 165 & & 165 & \\
\hline
\end{tabular}




\begin{tabular}{|c|c|c|c|c|c|c|}
\hline \multicolumn{7}{|c|}{$\begin{array}{ll}\text { Classical } \\
\end{array}$} \\
\hline & & \multicolumn{5}{|c|}{ Population Quintile } \\
\hline & Total & 1 & 2 & 3 & 4 & 5 \\
\hline $\begin{array}{l}\text { Markets Served by Public or } \\
\text { Commercial Stations }\end{array}$ & 88 & 12 & 9 & 13 & 28 & 26 \\
\hline Markets Served by Public Stations & 68 & 11 & 9 & 10 & 26 & 12 \\
\hline $\begin{array}{l}\text { Markets Served by Commercial } \\
\text { Stations }\end{array}$ & 28 & 2 & 0 & 3 & 4 & 19 \\
\hline $\begin{array}{l}\text { Simulated Markets Served by } \\
\text { Commercial Stations (with no } \\
\text { Public Stations) }\end{array}$ & 38 & 2 & 0 & 3 & 7 & 26 \\
\hline $\mathrm{N}$ & 165 & 34 & 33 & 32 & 34 & 32 \\
\hline \multicolumn{7}{|c|}{ Jazz } \\
\hline & & \multicolumn{5}{|c|}{ Population Quintile } \\
\hline & Total & 1 & 2 & 3 & 4 & 5 \\
\hline $\begin{array}{l}\text { Markets Served by Public or } \\
\text { Commercial Stations }\end{array}$ & 64 & 7 & 6 & 5 & 17 & 29 \\
\hline Markets Served by Public Stations & 36 & 5 & 4 & 2 & 9 & 16 \\
\hline $\begin{array}{l}\text { Markets Served by Commercial } \\
\text { Stations }\end{array}$ & 28 & 2 & 2 & 3 & 8 & 13 \\
\hline $\begin{array}{l}\text { Simulated Markets Served by } \\
\text { Commercial Stations (with no } \\
\text { Public Stations) }\end{array}$ & 31 & 2 & 2 & 3 & 8 & 16 \\
\hline $\mathrm{N}$ & 165 & 34 & 33 & 32 & 34 & 32 \\
\hline
\end{tabular}




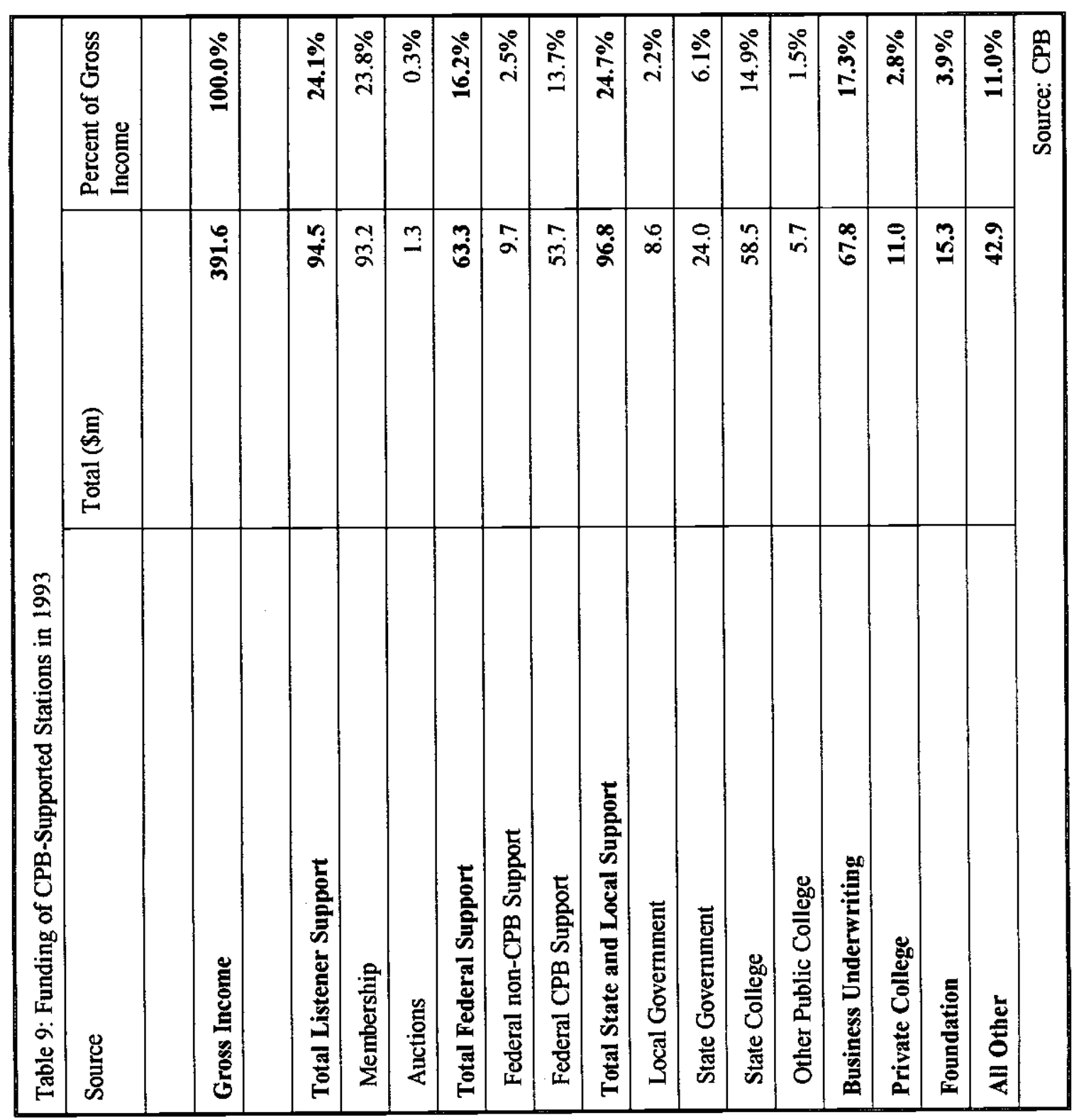

ำ 
Table 10: Government Support to Public Stations by Population Quintile and Degree of Commercial Competition (\$)

\begin{tabular}{|c|c|c|c|c|}
\hline \multirow[b]{3}{*}{$\begin{array}{l}\text { Population } \\
\text { Quintile }\end{array}$} & \multicolumn{4}{|l|}{ Classical Stations: } \\
\hline & \multicolumn{2}{|c|}{ Without Commercial Competition } & \multicolumn{2}{|c|}{ With Commercial Competition } \\
\hline & Federal & State and Local & Federal & State and Local \\
\hline 1 & 862,658 & 290,318 & 223,758 & 258,279 \\
\hline 2 & $1,886,094$ & $5,510,204$ & 0 & 0 \\
\hline 3 & $1,604,634$ & $2,451,588$ & 0 & 0 \\
\hline 4 & $4,173,332$ & $3,701,037$ & 201,985 & 40,971 \\
\hline 5 & $4,296,691$ & $2,327,518$ & $3,404,023$ & $1,657,538$ \\
\hline & \multicolumn{4}{|l|}{ Jazz Stations: } \\
\hline & \multicolumn{2}{|c|}{ Without Commercial Competition } & \multicolumn{2}{|c|}{ With Commercial Competition } \\
\hline $\begin{array}{l}\text { Population } \\
\text { Quintile }\end{array}$ & Federal & State and Local & Federal & State and Local \\
\hline 1 & 410,890 & $1,633,994$ & 0 & 0 \\
\hline 2 & 303,327 & $1,333,702$ & 0 & 0 \\
\hline 3 & 285,020 & 228,311 & 0 & 0 \\
\hline 4 & 887,799 & $1,566,934$ & 92,004 & 141,686 \\
\hline 5 & $1,032,319$ & $2,246,007$ & $2,347,666$ & $2,971,863$ \\
\hline
\end{tabular}


Figure 1

\section{Format Presence and Listening in 88 Markets with Data}

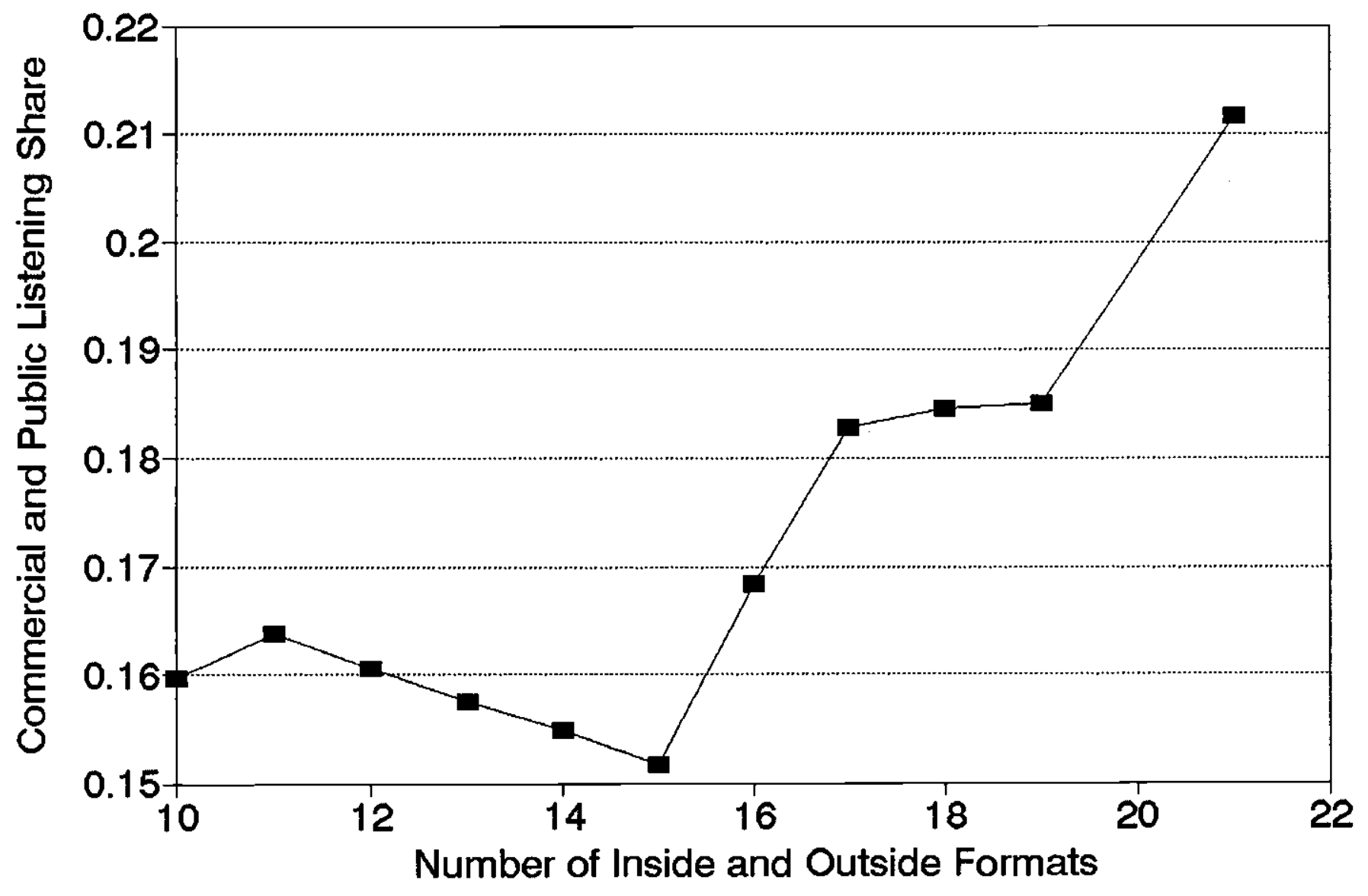


Figure 2

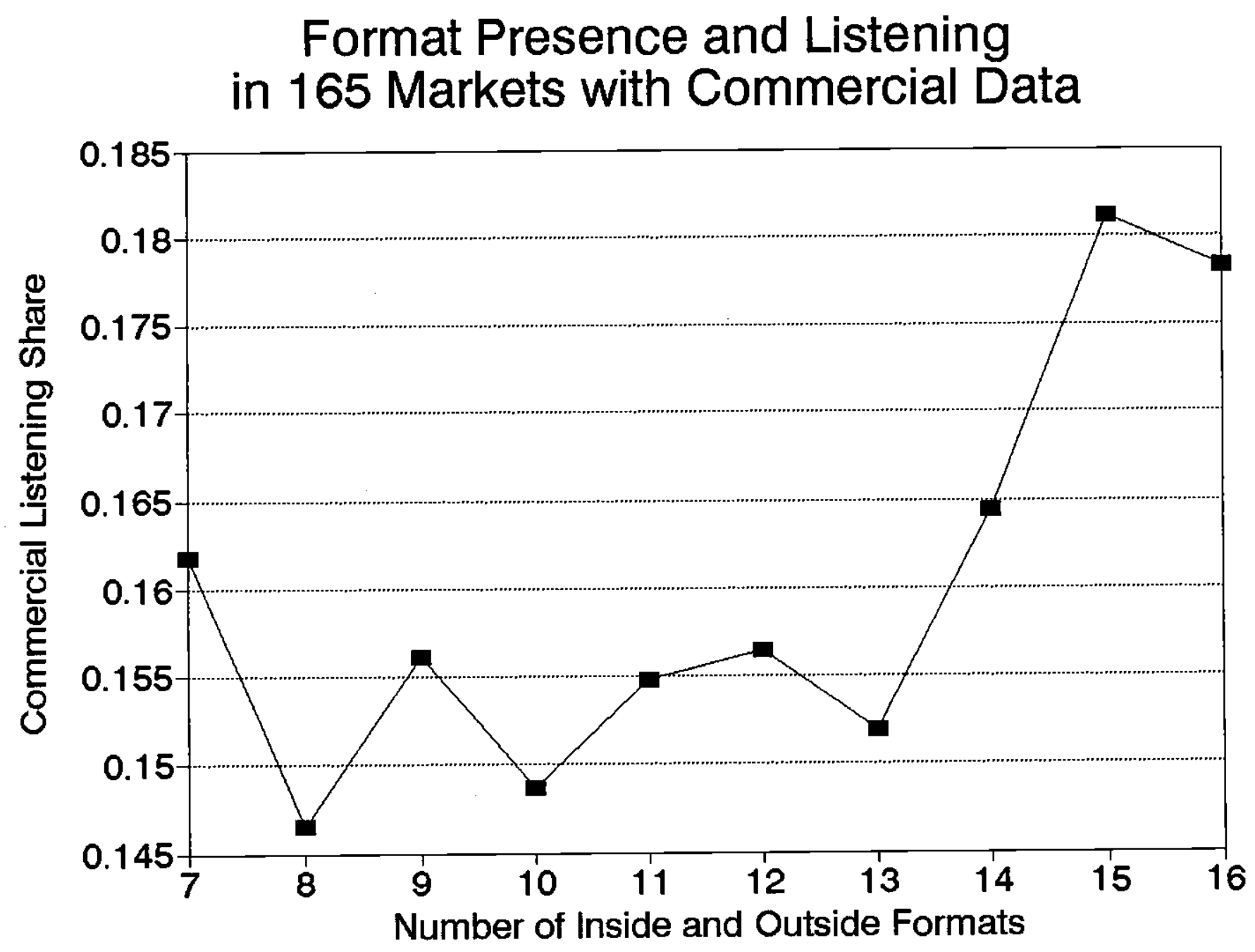

